\title{
EXPERIENCE OF MIDWIFERY STUDENTS ON OBJECTIVE STRUCTURED CLINICAL EXAMINATION: A SYSTEMATIC REVIEW
}

\author{
Nurul Huda, Dewi Rokhanawati, Nidatul Khofiyah \\ Study Program of Midwifery, Universitas Aisyiyah Yogyakarta
}

\begin{abstract}
Background: Objective Structured Clinical Examination (OSCE) has been widely accepted as a strategy for assessing clinical competence in various health related curricula (dentistry, pharmacology and physiotherapy). This has been established in nursing education and midwifery training. The purpose of this study was to review the experience of midwifery students about OSCE.

Subjects and Method: A systematic review were conducted by searching PubMed, ProQuest, and ScienceDirect databases. The inclusion criteria were: (1) Midwifery students; (2) Students who have not participated in OSCE; (3) Full text; (4) Articles published from 2008 to 2018; and (5) International journals. Appraisal studies used Critical Appraisal Skills Program (CASP) and the synthesis method used modification of PEOS.

Results: Articles about OSCE for midwifery were limited. Articles reported that OSCE could evaluate student clinical skill. OSCE could develop students' internal mental abilities before clinical field practice.

Conclusion: OSCE helps assess the knowledge about clinical practice among midwifery students.

Keywords: objective structured clinical examination, experience, midwifery students

\section{Correspondence:}

Nurul Huda. Study Program of Midwifery, Universitas Aisyiyah Yogyakarta, Yogyakarta, Indonesia. Email: nurulhuda0145@gmail.com. Mobile: 085360709858.
\end{abstract}

